\title{
Developing an efficient clinical information system for a comprehensive psychiatric institute: II. Initial evaluation form
}

\author{
JUAN E. MEZZICH, JOHN T. DOW, CHARLES L. RICH, ANTHONY J. COSTELLO, \\ and JONATHAN M. HIMMELHOCH \\ Western Psychiatric Institute and Clinic, University of Pittsburgh School of Medicine \\ Pittsburgh, Pennsylvania 15261
}

\begin{abstract}
This paper describes the objectives, design, organization, content, evaluation, and implementation of the initial evaluation form, first component of a comprehensive psychiatric institute's clinical information system. Major features of this effort are the involvement of a large number of clinicians in the form's development, the use of complementary narrative and standardized components, the use of an expanded DSM-III multiaxial diagnostic format, pilot testing with over 1,000 patients, the evaluation of the form's usefulness and interrater reliability, the form's computerization, facilitating data retrieval and coordination with other institutional data bases, and the form's monitoring.
\end{abstract}

A comprehensive assessment of a patient's condition constitutes the logical basis for the rational formulation of a plan for treatment. Furthermore, since at the Western Psychiatric Institute and Clinic (WPIC), as in many other psychiatric facilities, a patient gains admission to inpatient or outpatient care through a psychiatric evaluation at an entry station, the initial evaluation form (IEF) was selected as the most appropriate starting point for the design and implementation of the institute's clinical information system (CIS). Since work on the design of the IEF has been virtually completed, it will be used here to illustrate the developmental process planned for all components of the CIS.

The planning of the IEF benefited from previous thinking and experience on computerized information systems at the Department of Psychiatry of the University of Pittsburgh, both at WPIC (Dow, 1975; Kupfer,

A number of individuals at the Western Psychiatric Institute and Clinic have contributed ideas and work in the design and implementation of the Initial Evaluation Form. Particularly helpful in the initial planning and design stages were our colleagues on the clinical information system committee: $R$. Cohen, M. A. Darragh, T. Detre, N. French, P. Henderson, S. Hill, G. Hogarty, G. Huber, M. Kovacs, D. Kupfer, D. O'Donnell, V. Romoff, G. Roy, D. Wagener, and J. Wolford. Essential roles in the implementation of the IEF are being played by our collaborators in the Clinical Information System Group (G. A. Coffman, S. Goodpastor, and L. M. Axelson) and in the Diagnostic and Evaluation Center (B. Claypoole, D. Cox, S. Dachille, C. Davis, M. Davis, K. Evanczuk, E. Hazlett, R. Mathias, M. Reffner, S. Repta, R. Ruggieri, L. Sereles, J. Van Dyke, H. Capparell, M. Ganguli, D. Spiker, and R. Trivus). M. Maloney has provided competent and gracious assistance with the layout and printing of the form.
Levine, \& Nelson, 1976) and the Pittsburgh Child Guidance Center (Henderson, Magnussen, Snyderman, \& Homann, 1975). Other antecedents included some integral evaluation batteries for general psychiatric patients, such as the KDS system (Kupfer \& Detre, 1971) and the Comprehensive Psychiatric Assessment Schedule developed by Mezzich (Note 1), as well as the patient data system developed by Dow and the WPIC information systems program in 1975 for the computerized collection and retrieval of demongraphic and financial information.

\section{OBJECTIVES}

Through questionnaires and discussions with potential users throughout WPIC, a set of user objectives was developed for the initial evaluation procedure. These users can be classified into patient evaluators, educators, treatment program staff, researchers, and administrators.

Objectives identified for patient evaluators include improvement of the patient assessment process through the establishment of guidelines for narrative description and standardized ratings of key clinical data, more efficient retrieval of previous initial evaluation data (via an on-line terminal in the assessment area), speeding up and optimizing a new evaluation, enhancement of the appropriateness and accuracy of treatment program assignment, and obtaining systematic feedback on the quality of the evaluation and the appropriateness of dispositions made.

Objectives for the staff of the treatment program receiving the patient include the availability of reliable and accurate evaluation information useful for making 
initial clinical management decisions, determining which additional assessments are necessary, preparing the treatment plan, and serving as a baseline to describe treatment course and outcome.

Objectives for educators involve the provision of structure and guidelines for a comprehensive psychiatric assessment conducted by trainees and the facilitation of supervision and systematic feedback to the clinical evaluators on the assessments made.

Objectives for researchers involve the efficient identification of patients appropriate for research protocols at the time of initial contact through a computerized procedure that obviates a tedious, error-prone manual search through the charts of many patients. Objectives also involve the availability of the IEF data base for clinical and epidemiological studies.

Objectives for administrators include the availability of systematic and readily retrievable data on the number and types of patients applying for care and admitted to the various treatment programs available. This can assist in the planning and monitoring of clinical services, as well as in the preparation of statistical reports required by governmental and other external agencies.

\section{DEVELOPMENT}

\section{Selection of Informational Items and Sections}

One of the most important aspects of the development of the IEF was determining which data to collect and how to collect them. A questionnaire facilitated the participation of WPIC staff in this process. It contained a brief introduction, samples of narrative and standardized items, and a questionnaire. For each prospective narrative section (e.g., history of present illness), the following questions were formulated: Is it useful? Is it well evaluated currently? And is it easily evaluated in an initial evaluation setting? For each of the prospective standardized items (e.g., age, presence of depressive delusions), the following questions were posed: Is it irrelevant or is it useful as an exclusion or inclusion criterion for your program? Is it useful for making management decisions? And is it useful for providing a concise description of the patient's clinical condition?

Visits were then scheduled with 38 programs, including clinical evaluation, clinical treatment, clinical research, nonclinical research, and administrative groups. The visits were planned to explain the objectives of the CIS and the IEF, invite comments and suggestions, introduce the questionnaire, and answer questions. Typically, each visit lasted $1 \mathrm{~h}$ and involved the participation of two or three program members representing various professional backgrounds. A second visit was requested by some programs interested in clarifying aspects of the questionnaire and their relationship to initial patient evaluation.

Seventy-eight complete individual questionnaires (all but one of all questionnaires distributed) were received, and their structured and narrative responses were analyzed.

Most of the proposed narrative sections were perceived as quite useful in principle. However, several were seen as not well evaluated at that time, especially the sections on personal and social history and the review of systems. Also, some sections (e.g., extensive family history), although useful in general, were seen as not easily assessed at the initial evaluation point, but as more appropriate for a "second phase" of the evaluation of the patient at WPIC.

In regard to the proposed standardized demographic items, it was felt that additional work was needed to make them more readable. Most proposed items were considered useful, and there were a number of suggestions to add additional items (e.g., members of the household) and to modify the scale of some existing items (e.g., assessment of occupation, education, and social class).

Almost all of the proposed symptom checklist items were seen as useful for providing a concise description of the patient. The perceived usefulness of these items for management purposes was only slightly lower. With respect to the purpose of selecting patients for specific programs, most items were seen by fewer than half of the respondents as having such value for their program. Several additional items were suggested, especially to make the symptom checklist more appropriate for the evaluation of children. In regard to historical items, those dealing with length and course of psychopathology were seen as useful by $80 \%$ or more of the respondents, and those dealing with previous treatment were considered useful by $70 \%$ or so of the respondents. All axes of the comprehensive multiaxial diagnostic formulation proposed were seen as useful by $85 \%$ or more of the respondents.

\section{Form Design}

On the basis of the comments and suggestions received, preliminary decisions were made on the data to be obtained. Efforts were then concentrated on the design of the IEF

The standardized forms used by administrative interviewers to collect demographic and financial information under the previously developed patient data system became the demographic and financial sections of the IEF, after the format of some items were changed and some new ones were added.

The previous instrument used in the institute for the clinical evaluation of patients applying for psychiatric care was strictly narrative and could not be computerized in a way that would allow for efficient retrieval of information. It was decided that the clinical section of the IEF would include a narrative component to allow flexibility in the description of the patient's condition, as well as a standardized component to ensure the systematic gathering of key clinical information and its efficient processing and retrieval. Furthermore, an 
Table 1

Format of Initial Evaluation Form

Demographic information

Financial/insurance information

Reason for referral and evaluation

History of present illness

History of other psychiatric disorders

Mental status observations

Family history

Personal and social history and current social

support systems and assets

Medical history, systems review, and examination

Narrative assessment summary, problem list

and recommendations, plans for family members

Evaluators' signatures
Psychiatric history markers

Some problems in the past and in the current episode

Complementary symptom inventory

Family history markers

Personal and social history and social isolation markers

Presence/absence of positive general medical findings

Diagnostic summary and disposition

Evaluator's codes and signature dates attempt was made to integrate related narrative and standardized subsections to facilitate their completion.

Table 1 presents the basic format of the IEF, including a list of its sections and subsections.

\section{Pilot Testing}

Extensive trial runs of successive drafts of the IEF were conducted at the main entry gate to WPIC, the Diagnostic and Evaluation Center, as well as in other units of the institute. These trial runs gave evaluators first-hand, intensive experience with the IEF by using it for over 1 year with more than 1,000 psychiatric patients presenting a wide variety of psychopathological conditions. During the first months, a structured form was completed by the clinical evaluator each time that the IEF was used in order to provide comments and suggestions. From time to time, meetings were held with line clinicians and program directors in which the trial runs were discussed and specific suggestions for improvement of the IEF were requested. This enabled detection of problems in the use of the IEF, collection of data on the operation of the IEF, and the working out of procedures for a smoother initial evaluation process. On the basis of this pilot experience, the original April 1979 draft of the IEF was revised in July 1979 and again in June 1980.

Throughout the process of designing the IEF, a pointed effort was made to maintain the quality of each version. Proof sheets returned from the printers were carefully inspected to be sure that spelling and organization were correct. This step was taken so that a clinician reviewing the form would not be distracted by minor errors. Such errors could result in a bad impression of the IEF, which would be reflected in reduced acceptance of the form.

Some of the most interesting findings of the pilot test included the following: (1) The new, more comprehensive IEF took about the same amount of time to complete as the old narrative form, after the evaluator became familiar with it, and (2) the successive versions of the IEF were increasingly perceived by the clinicians as providing an accurate and useful description of the patient's condition.

\section{CURRENT VERSION OF THE IEF}

Figures 1-10 show the current 1980 version of the IEF. The first sections are the demographic and the financial sections, each one page long. These are fully standardized and are completed by an administrative interviewer.

The clinical section has as a main structural feature the mutually complementary arrangement of narrative and standardized components to facilitate completion. A highlight of the form is its inclusion of an expanded DSM-III (American Psychiatric Association, 1980) diagnostic formulation format in its last page (Figure 10). This is addressed to maximize the merits and potential of multiaxial psychiatric diagnosis (Mezzich, 1979, 1980) and to provide sounder grounds for the subsequent preparation of a comprehensive treatment plan. While the last DSM-III axis (V: "Highest level of functioning in the past year") appears to have mainly prognostic value (i.e., prediction of level of functioning after a florid episode of illness has subsided), the added Axis VI ("Current functioning") has considerable management value (e.g., to assist in hospitalization decisions and in planning work and social skills training).

The recording space of the clinical section spans eight pages. Extra blank pages (with patient and evaluation setting identification provided) are available to supplement any of the basic pages. In addition to the version of the form presented here, which provides blank spaces for typing narratives, a lined version is also available for handwriting narratives.

In addition to brief instructions and definitions provided directly on the form for all sections and items included, instructions and a list of terms and codes for Diagnostic Axes I through VI are provided on the back of the last pages of the form.

\section{EVALUATION}

In 1980, a copy of the current version of the IEF was sent to clinicians on the full-time faculty and stafl of WPIC, along with a questionnaire to assess the per ceived quality of the IEF according to five 4-poin scales. One hundred and two completed questionnaire: 
UN I VERS ITY OF PITTSBURGH

WESTERN PSYCHIATRIC INSTITUTE AND CLINIC

Page 1 of 2 INITIAL EVALUATION FORM - DEMOGRAPHIC SECTION

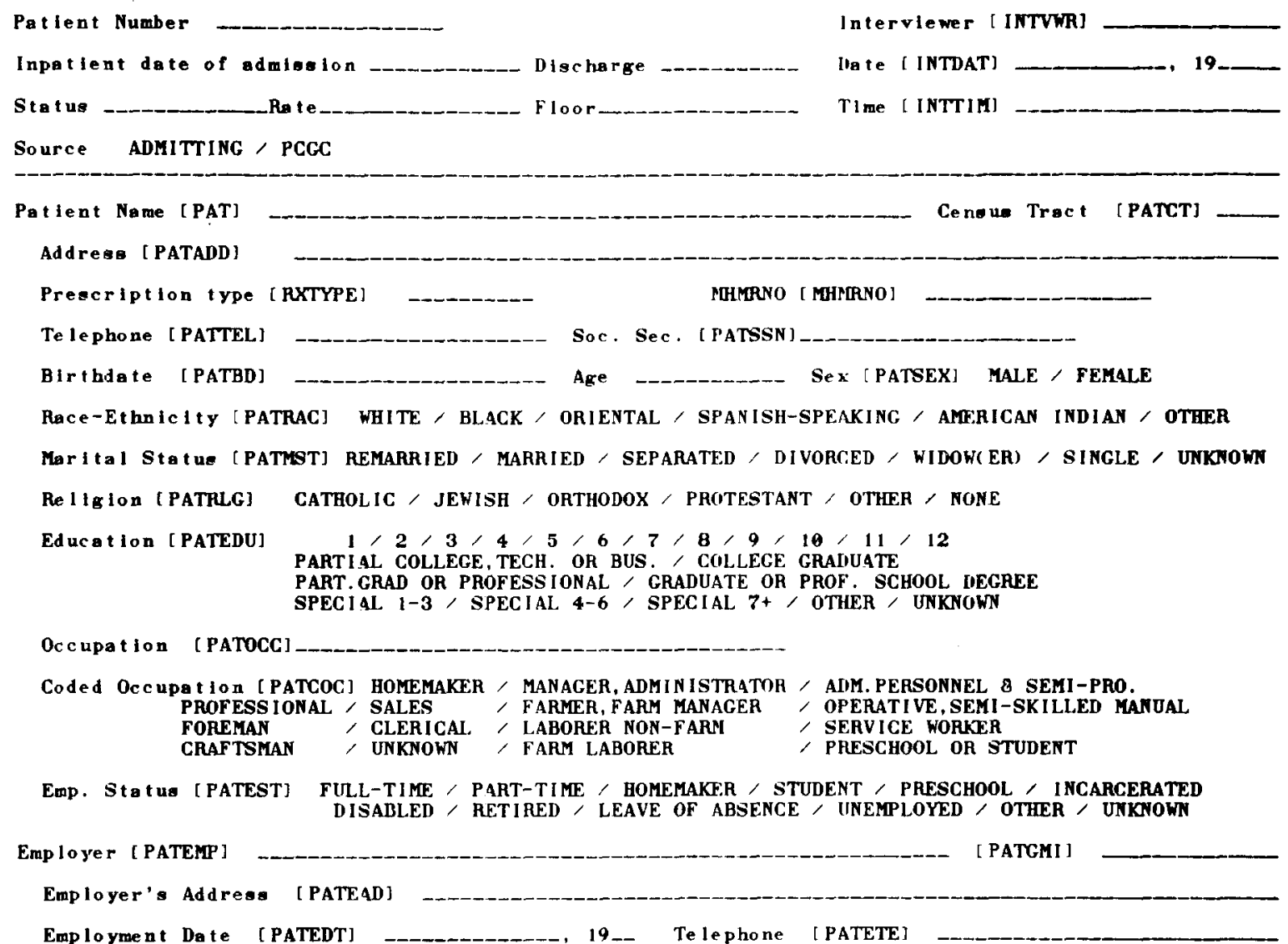

Residing with [ PATCOH] SPOUSE / PARENT(S) / RELATIVES(OTH) / FRIEND / FOSTER HONE / OTHER / NONE

Age 3 Sex of those in household [HAGSX]

Head of Household [PATHEA] YES / No

Education of Head of Household (if not pattent) [HHEDU]

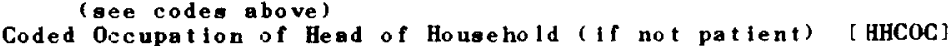

(see codes above)

Spouse/nearest rel/friend [REL]

Re lationghip [RELRLL] SPOUSE, MOTHER / FATHER / SON / DAUGHTER / SISTER / BROTHER / FRIEND / OTB

Addresa [RELADD ]

Te le pho ne [ RELTEL]

Name of person who referred patient [REF]

Re lat longhip [REFREL] SELF， FAMILY， FRIEND / HEALTH PAOFESSIONAL / CLEAGY

SOCIAL ACENCY , MASS MEDIA / COURT / POLJCE / OTHER / UNKKOWN

Name of person who accompanied patient [ACC]

Re lationship [ ACCREL] SELF / SPOUSE / RELATIVES (OTH) / FRIEND / HEALTH PROFESSIONAL

POLICE / PHOBATION OFF. / COUNTY ADMIN. ' AGENCY (OTH) / OTHER / UNKNOWN

Agency [AGENCY]

Remark

$06 / 17 / 80$ Revision 


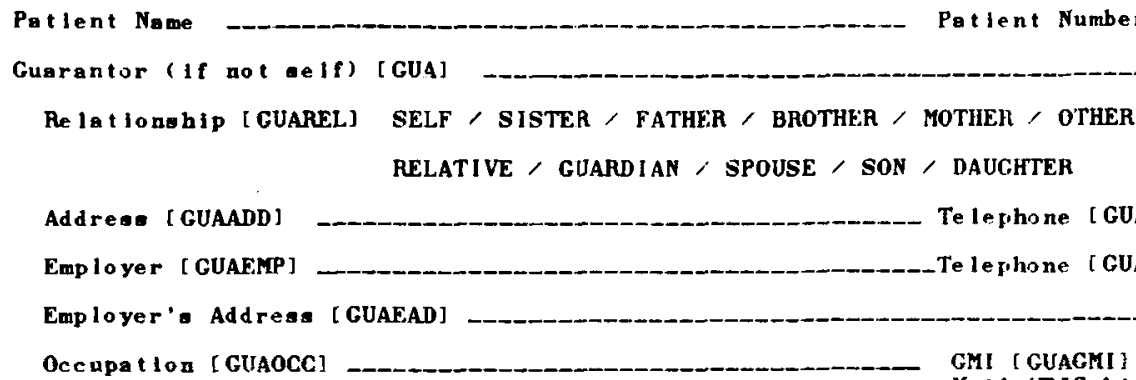

If hospltallzed within last 12 monthe, where and how long [HOSP]

Financ ia 1 Hemark [ F INRMI]

Financ la l Remark [ F INRM2]

Finane la l Remark [ FINRM3]

I underatand that Western Paychiatric Institute and Clinie (WPIC) is required by Pennsylvania State Law to be Teaching Hospital, and that supervised students may therefore particlpate in the treatment provided to me.

I hereby certify that the above otatements are true and I approve an Investigatlon by the hospltal of my financial status. I agree to assume full responsibility for the expenses lncurred by the bove pattont during hospltalization.

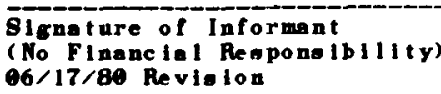

Signature of hesponsible Person

Figure 2. 
INITIAL EVALUATION FORM

CLINICAL SECTION

(6/16/80 Revision)
Name:

WPIC Number:

Date:

m

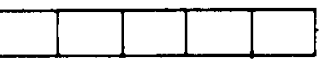

d

y

Evaluation Setting:

Recent evaluation completed at WPIC: Evaluation setting:

Date:

I

REASON FOR REFERRAL AND EVALUATION: (Including chief complaint)

HISTORY OF PRESENT ILLNESS (Start with current episode. Then describe in separate paragraphs all previous episodes of the present illness. For each episode narrate onset and course of precipitating/maintaining factors, symptoms, repercussion on social functioning and treatment received. Include use of alcohol and other drugs and evidence of dangerousness to self and others.) 
WPIC Number:

HISTORY OF OTHER PSYCHIATRIC DISORDERS (Manifestations and treatment of currently inactive psychiatric disorders and of personality disorders which preceded present illness, to be used as background information. Include a description of any past problems noted in the checklist below).

\section{PSYCHIATAIC HISTORY MARKERS}

(Use question marks for unknown days, months, or years)

1. Regarding present psychiatric illness:

a. Approximate date of onset of current episode:

b. Approximate date of onset of first episode of present psychiatric illness:

c. Baseline course since first onset of present psychiatric illness:

d. Episodicity of present psychiatric illness:

$$
\frac{1}{\mathrm{~m} d y}
$$

$$
\frac{1}{m \text { d } y}
$$

$\square$ Improving $\square$ Stationary $\square$ Worsening

$\square$ Continuous or single episode

$\square$ With clear cut episodes

$\sqcap$ Fluctuating. without clear cut episodes

2. Approximate date of onset of past psychiatric disorders (if any)

$$
\frac{1}{m \text { d } y}
$$

$\square$ None

3. Date of first psychiatric hospltalization ever:

$$
\frac{1}{\text { month year }} \square \text { Never hospitalized }
$$

4. Number of months of psychiatric hospitalization during the past 12 months:

6. Mental Health treatment during the past 3 months (check ail applicable):

$\begin{array}{lll}\square \text { None } & \square \text { Neuroleptics } & \square \text { Anticonvulsants } \\ \square \text { Individual psychotherapy } & \square \text { Minor tranquilizers } & \square \text { Other \& unspecified medication } \\ \square \text { Group psychotherapy } & \square \text { Antidepressants } & \square \text { ECT } \\ \square \text { Family therapy } & \square \text { Lithium } & \square \text { Other modalities }\end{array}$

SOME PROBLEMS IN THE PAST AND IN THE CURRENT EPISODE

Present Present

in past in

but not current Not

Absent current episode known

1. INSOMNIA

difficulty falling or

staying asleep.

and/or early morn

ing awakening

2. HYPERSOMNIA

excessive amount

of sleep

3. APPETITE LOSS

4. APPETITE GAIN

5. WEIGHT LOSS

6. WEIGHT GAIN

7. LOSS OF LIBIDO lack of sexual interest or activity

8. HYPEREXCITED LIBIDO

9. ALCOHOL USE of concern to individual or significant other

10. USE OF OTHER C.N.S. DEPRES SANTS

barbifurates, other hypnotics, minor tranquilizers

11. USE OF OTHEA DRUGS

stimulante, nar

cotlc anaigesics.

marijuane, hallu-

cinogens, cocaine

12. VIOLENT BEHAV. IOA aggressiveness

13. IMPULSIVITY poor impulse control

14. OTHER ANTISOCIAL BEHAVIOR cheating, stealing. irresponsibility. callousness

Figure 4. 
Page 3

WPIC Number:

MENTAL STATUS OBSERVATIONS

I. General Appearance and Behavior

II. Speech and Thought Rate and Pattern

III. Mood and Affect
COMPLEMENTARY SYMPTOM INVENTORY

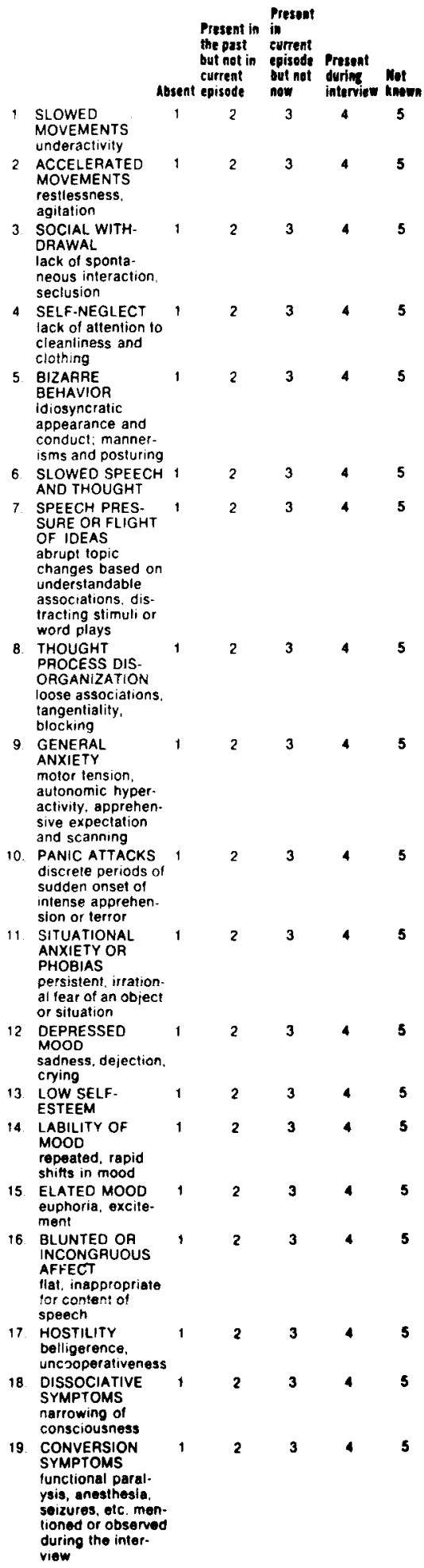

Figure 5. 
IV. Thought Content and Perception

V. Sensorium, Orientation, Intellectual Functions and Insight

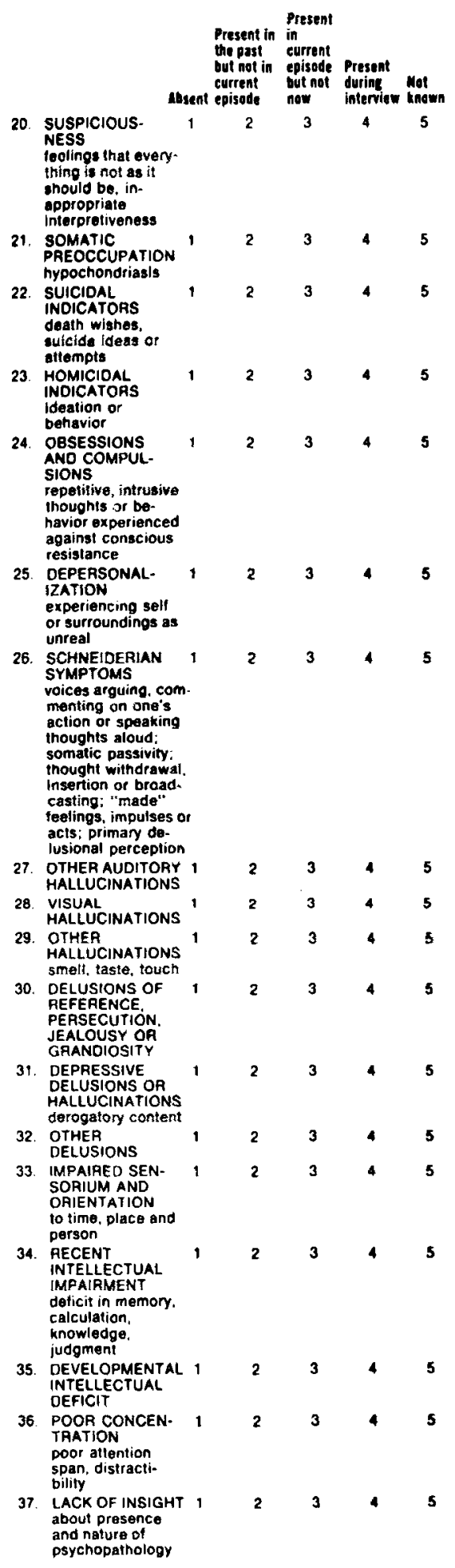

Figure 6. 
WPIC Number:

Page 5

\section{FAMILY HISTORY}

Past and current psychiatric and major general medical disorders and treatment in the family.

\begin{tabular}{|c|c|c|}
\hline & No & Yes \\
\hline $\begin{array}{l}\text { 1. Psychiatric disorders in } \\
\text { the family }\end{array}$ & 1 & 2 \\
\hline $\begin{array}{l}\text { 2. Psychiatric treatment } \\
\text { received }\end{array}$ & 1 & 2 \\
\hline $\begin{array}{l}\text { 3. Major general medical } \\
\text { disorders in the family }\end{array}$ & 1 & 2 \\
\hline $\begin{array}{l}\text { 4. General medical treat- } \\
\text { ment received }\end{array}$ & 1 & 2 \\
\hline
\end{tabular}

PERSONAL AND SOCIAL HISTORY

Developmental, educational, marital, sexual, military, occupational and legal history. Current social support system and assets useful for treatment planning

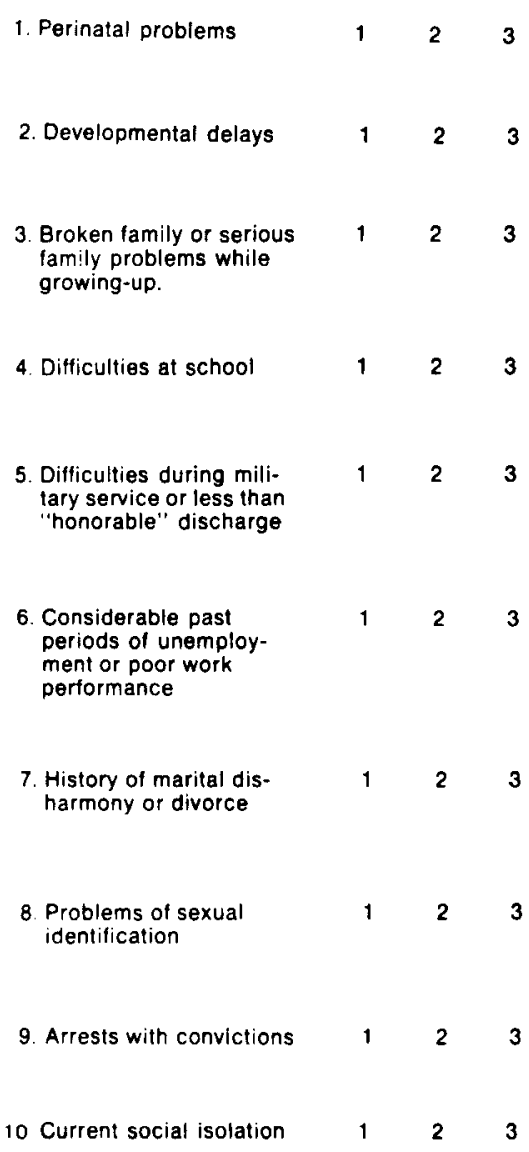

Figure 7. 
MEDICAL HISTORY (Major non-psychiatric illnesses, physical complaints and injuries, hospitalizatlons, operations, obstetric \& gynecological history, current physicians and medications, drug sensitivities and allergies)

See separate medical note

Positive history of serious medical problems: $\square$ No $\square$ Yes $\square$ ?

REVIEW OF PHYSICAL SYSTEMS (Positive and pertinent negative physical symptoms)

See separate medical note

Significant positive physical symptoms: $\square$ No $\square$ Yes $\square$ ?

\section{PHYSICAL EXAMIMATION}

$\square$ See separate medical note

Vital Signs: Pulse

BP

Temp.

Resp

Positive and pertinent negative findings: 
Page 7

WPIC Number:

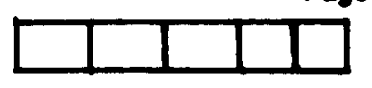

NARRATIVE ASSESSMENT SUMMARY 
UNIVERSITY OF PITTSEURGH

WESTEF.. PSYCHIATRIC INSTITUTE AND CLINIC

INITIAL EVALUATION FORM CLINICAL SECTION
Name:

WPIC Number:

Date:

Date. $m$ Selting:

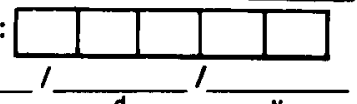

:

DLAONOSTIC SUMMARY

1. Clinical psychiatric syndromes (instructions and codes on back of pages 6 and 7)

Codes

Main Formulation:

1.

2.

3.

4.

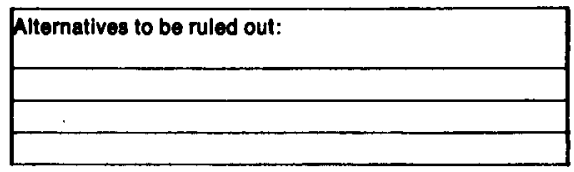

11. Personality and specific developmental disorders (Instructlons and codes on back of pages 6 and 7 ):

Main Formulation:

1.

2.

3.

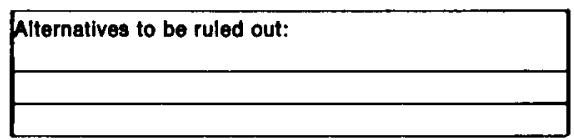

III. Physical disorders (instructions on back of thls page):

Main Formulation:

1.

2.

3.

IV. Psychosocial stressors (instructions on back of this page):

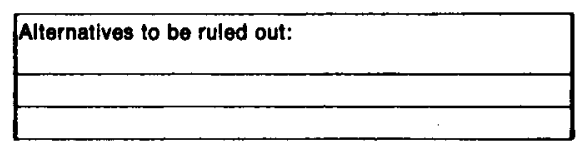

A. Ranked list:

1.

2.

4.

B. Overall

stressor

severity:

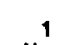

1 None

$\stackrel{2}{\text { Minimal }}$

$\stackrel{3}{3} \quad$ Moderate

5
Severe

$\stackrel{8}{\text { Extreme }}$

Catastrophlc

$\stackrel{0}{\text { Unseclfied }}$

V. Highest level of adaptive functioning during the past year (instructions on back of this page):

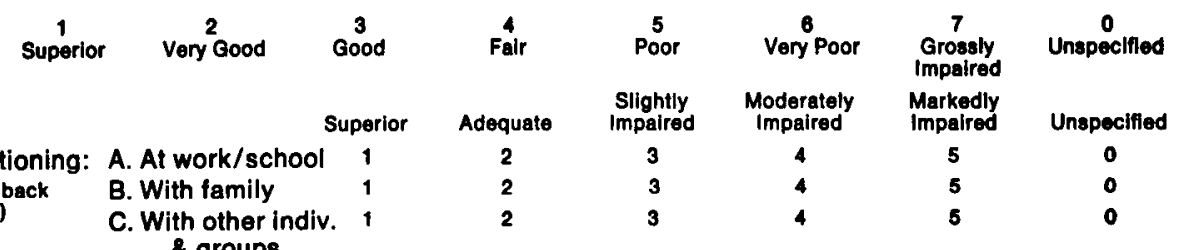

VI. Current functioning: of this page) \& groups

\section{DISPOSITION}

A. Admission or Referrals

\begin{tabular}{|l|l|l|l|}
\hline Name of program or facility & $\begin{array}{c}\text { Oate of admission } \\
\text { or appointment } \\
\text { (month/day/year) }\end{array}$ & $\begin{array}{c}\text { Program } \\
\text { code } \\
\text { (by coder) }\end{array}$ & $\begin{array}{c}\text { Flow sheet } \\
\text { sent } \\
(v)\end{array}$ \\
\hline & & & \\
\hline & & & \\
\hline
\end{tabular}

B. Legal status after evaluation:

$\square$ voluntary (regular)

$\square$ Voluntary-302

$\square 302$ Commltment $\square 303$ Commitment

$\square 304$ Commitment Commltment dis- in force conttnued

\section{EVALUATORS}

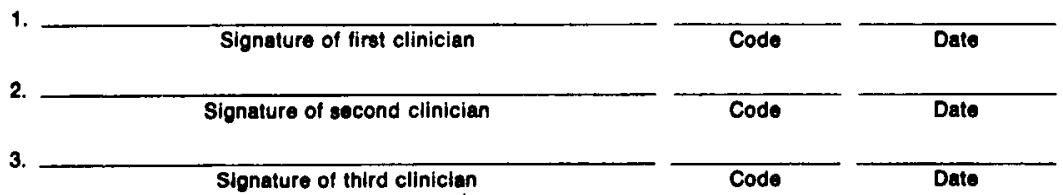

Figure 10. 
Table 2

Ratings (in Percentages) of the Quality of the Initial Evaluation Form as Perceived by 102 Clinicians at WPIC

\begin{tabular}{lccc}
\multicolumn{1}{c}{ Question } & \multicolumn{2}{c}{ Rating } \\
\hline & $\begin{array}{c}\text { Very } \\
\text { Good }\end{array}$ & $\begin{array}{c}\text { Fairly } \\
\text { Good }\end{array}$ & $\begin{array}{c}\text { Rather } \\
\text { Poor }\end{array}$ \\
\hline $\begin{array}{l}\text { Very } \\
\text { Poor }\end{array}$ \\
(1) Organization of the informational sections & 79 & 18 & 3 \\
(3) Clarity of the items included & 74 & 24 & 0 \\
(4) If you have had the opportunity to use this version of the form & 61 & 39 & 1 \\
(a) How well did it convey the evaluation of the patient? & 52 & 47 & 0 \\
(b) How convenient and easy was it to use? & 30 & 59 & 1 \\
\hline
\end{tabular}

were received. The ratings are summarized in Table 2. For all items, $89 \%$ to $100 \%$ of the ratings were at one of the two highest levels ("very good" or "fairly good"), with the large majority of ratings being at the "very good" level.

Additional evidence of the acceptance and usefulness of the form was provided by an independent study conducted by the WPIC patient care audit committee on IEFs completed during the first month of use of the current version of the form. Even during this introductory period, the vast majority of sections and items of the IEF were found to be satisfactorily completed. Furthermore, supporting the diagnostic documentation value of the IEF, it was found that in $83 \%$ of the cases there was adequate clinical information recorded in the body of the form to satisfy the criteria required in the DSM-III manual for the diagnoses made.

Preliminary assessments of the interrater reliability for the items of the IEF have found quite high levels of agreement. Agreement appears to increase with the level of training.

\section{IMPLEMENTATION ACTIVITIES}

\section{Training of Evaluators}

An important aspect of the implementation of the form is the training of clinical evaluators who complete the IEF. This is an ongoing program, so it will involve not only current, but also future evaluators. The training program currently includes the following components.

(1) Demonstration of interview techniques by senior WPIC clinicians: These are invited to conduct a live psychiatric interview of selected patients with IEF clinical evaluators either present in the room or watching through a one-way mirror. After the patient leaves, a discussion of the interview process and the diagnostic formulation takes place.

(2) Individual practice and group discussion of ratings of videotaped diagnostic interviews: Each participating clinician independently completes an IEF upon watching a videotaped diagnostic interview. After the ratings are collated, a group meeting is held to discuss problems encountered and areas of disagreement.

(3) Peer review of routinely completed IEFs: A sample of routinely completed IEFs is selected to be periodically reviewed by the whole group of initial evaluators in order to monitor the completion and quality of the write-ups.

\section{Data Base Development and Processing}

The data obtained with the IEF and checked for completion and clarity by a systems specialist and then are entered into in-house minicomputers at WPIC. These computers already support the institutional patient registration, contact, and billing systems. The data collected with the IEF and other CIS forms are being integrated with these other systems. This should allow an efficient use of computer resources, as well as increased flexibility in obtaining a more comprehensive view of each patient.

Another important aspect of the computerization of the IEF consists of developing procedures and computer programs with which users can retrieve data. The reasons for data retrieval span patient care, clinical/administrative reporting, and research. Data retrieval for patient care mainly involves data from an IEF previously completed for the patient at hand. The retrieval of the narrative information contained in the IEF requires a manual search in the patient's paper chart. In contrast, the standardized sections of the IEF can be retrieved very quickly from the computer through video display terminals.

The standardized information is also retrieved for the purpose of identifying candidates for specific research protocols. Summary reports and data-based research usually require large amounts of data. Since the computer programs required to generate summary reports are relatively simple, these can be generated on the in-house minicomputers. On the other hand, data-based research studies often require special software not available on these computers. These data can be placed on a magnetic tape, with appropriate confidentiality measures taken, and processed on the university's large computer system, which has the software and machine capacity to handle most research needs.

\section{Systems Monitoring}

Many computerized information systems work very well for some time after implementation. In other cases, as soon as the designers of the system turn to other projects, the system begins to fall apart. This may 
be due to laxity on the part of the operators or to inadequately trained or motivated clinical staff. These problems can be detected if a routine program of monitoring the operation of the system is implemented. Two of the most important elements are reliability and validity.

Monitoring the reliability of the CIS evaluation forms involves having multiple clinicians evaluate the same patient, through either a live or a videotaped interview. In this way, a measure of interrater agreement can be obtained (Bartko \& Carpenter, 1976; Mezzich, Kraemer, Worthington, \& Coffman, 1981).

Monitoring the validity of the CIS is more difficult than monitoring its reliability. One activity planned for assessing the usefulness of the IEF is to have the staff of the receiving treatment module judge the quality of the evaluation and the appropriateness of the referral made and record this judgment. Another activity involves assessing empirically the value of the clinical information contained in the IEF to substantiate diagnostic formulations and treatment referrals. More generally, the continuous acceptability of the IEF can be assessed through meetings with evaluators and the staffs of the treatment programs, as well as through the circulation of periodic questionnaires throughout the institute.

\section{COMMENT}

The IEF now has become the standard form for the initial evaluation of patients at WPIC. The current institutional policy is that the chart of every inpatient and outpatient cared for at the institute must have a completed IEF. However, the form should not be considered fossilized. In fact, it will undergo periodic scrutiny in order to revise it as needed. This process is facilitated by the flexibility of the design and computerization arrangements.

\section{REFERENCE NOTE}

1. Mezzich, J. E. Manual of the comprehensive psychiatric assessment schedule (technical report). Stanford, Calif: Stanford University, Department of Psychiatry and Behavioral Sciences, 1977.

\section{REFERENCES}

American Pgychintric Agsocintion. Diagnostic and statistical manual of mental disorders (3rd ed.) (DMS-III). Washington, D.C: Author, 1980.

Bartxo, J. J., \& Carpenter, W. T. On the methods and theory of reliability. Journal of Nervous and Mental Disease, 1976, $163,307-371$.

Dow, J. T. Designing computer software for information systems in psychiatry. Computers in Biomedical Research, 1975, 8, 538-559.

Henderson, P. B., Magnussen, M. G., Snyderman, B. B., \& HomanN, J. A clinical decision-making model for child psychiatric intervention selection. Psychological Reports, 1975, 37, 923-934.

Kupren, D. J., \& Detre, T. P. KDS systems. New Haven, Conn: Kupfer-Detre Systems, 1971.

Kupfer, D. J., Levine, M. S., \& Nelson, J. A. Mental health information systems: Design and implementation. New York: Marcel Dekker, 1976.

Mzzzich, J. E. Patterns and issues in multiaxial psychiatric diagnosis. Psychological Medicine, 1979, 9, 125-137.

Mezzich, J. E. Multiaxial diagnostic systems in psychiatry. In H. I. Kaplan, A. M. Freedman \& B. J. Sadock (Eds.), Compre. hensive textbook of psychiatry (3rd ed.). Baltimore: Williams \& Wilkins, 1980.

Mezzich, J. E., Kraemer, H. C., Worthington, D. R. L., \& Cofrman, G. A. Assessment of agreement among several rater: formulating multiple diagnoses. Journal of Psychiatric Research, $1981,16,29-39$. 